\title{
Male influence on oestrous cycles in female woolly opossum (Caluromys philander)
}

\author{
M. Perret and S. Ben M'Barek \\ CNRS URA 1183, M.N.H.N. Laboratoire d'Ecologie Générale, 4 avenue du petit Château, \\ F91800 Brunoy, France
}

\begin{abstract}
Summary. Plasma progesterone concentrations and the occurrence of oestrous cycles were studied in isolated woolly opossums subsequently subjected to male influences during a 40-day period. Pairing $(N=48)$ or exposure to male urine $(N=15)$ resulted in all females exhibiting oestrous during the stimulation phase, providing evidence that the activation of ovarian activity in the woolly opossum involves pheromonal cues from males. The latency of occurrence of oestrous in stimulated females depended upon their sexual state before male stimulation. In anoestrous females, the mean latency was $20.7 \pm 0.9$ days $(N=35)$, a value which agrees with the duration of the follicular phase. In females which first entered oestrous before male stimulation, the latency of induced oestrous was inversely correlated to the date of occurrence of the previous oestrous. The inter-oestrous interval was normal $(38 \cdot 1 \pm 1$ days, $N=5)$ when females were in oestrous at the beginning of male stimulation. In contrast, the inter-oestrous interval was significantly shortened $(28.7 \pm 2$ days, $N=7)$ or lengthened $(51 \cdot 1 \pm 1 \cdot 7$ days, $N=16)$ depending on whether females were in the luteal or follicular phases at the beginning of male stimulation. During pairing several females became pregnant and gave birth $24 \pm 0.9$ days $(\mathrm{N}=13)$ after copulation.

In the woolly opossum, the response to male influences involves mechanisms similar to those observed in eutherians and results in enhancement and synchronization of oestrous cycles in females. Pheromonal interactions could play an important role in synchronizing oestrous cycles in wild females during the dry season, a period when animals regroup to feed on spatially localized food resources.
\end{abstract}

Keywords: male effect; pheromone; oestrous cycles; progesterone; marsupial

\section{Introduction}

In mammalian species that have spontaneous ovarian cycles, physical and social signals from the environment can alter the endogenous rhythm of ovarian activity. Various influences of males upon the timing of fertility in females are well documented and known as "the male effect". In rodents or domestic mammals, the presence of an adult male or chemical cues from such a male influences the ovarian activity of females: acceleration of puberty, enhancement and synchronization of oestrous cycles (reviews by Signoret, 1980; Bronson \& McMillan, 1983; Izard, 1983; McClintock, 1983). Within marsupials, the influence of males on periodicity of oestrous in females has been little investigated, perhaps because of the relative paucity of available information on hormonal patterns during oestrous cycles and the lack of experimental studies on social factors with captive marsupials. Nevertheless, for some marsupial species, several authors have stressed the role of the male on oestrous synchrony (Sminthopsis: Smith et al., 1978; Antechinus: Dickman, 1985) and the stimulatory effect of pairing on occurrence of oestrous (Antechinus: Pellissier-Scott, 1986; Monodelphis: Fadem, 1985, 1987; Fadem \& Rayve, 1985; Baggott et al., 1987). In Monodelphis, 
oestrous can be induced in anoestrous females by transferring them to cages soiled by a male (Fadem, 1989).

The woolly opossum, Caluromys philander, is a didelphid marsupial widely distributed in northern and eastern neotropical forests of South America. This polyoestrous species breeds seasonally when food supply is abundant (Atramentowicz, 1982; Charles-Dominique, 1983). In French Guyana, births occur synchronously at the end of the dry season (Atramentowicz, 1982), implying that synchronized oestrous periods occur early (Perret \& Atramentowicz, 1989). Success in lactation, which lasts 4 months, appears to be correlated with high food availability: the first litter is always successfully weaned whereas the second litter usually fails. If the decline in food resources is assumed to cause the cessation of reproduction in this arboreal and frugivorous species, the determinant factor for the onset of seasonal sexual activity is presently unknown.

In captivity under constant environmental conditions, woolly opossums demonstrate circannual rhythms of sexual activity which are not synchronized between sexes (Perret \& Atramentowicz, 1989). Spontaneous oestrous cycles are present in captive females, independent of variations of food resources. Since a stimulating effect of females upon plasma testosterone concentrations of males has been described (Perret \& Atramentowicz, 1989), social cues would seem to be important to co-ordinate reproductive events in the woolly opossum.

The purpose of this study was to test whether ovarian activity of woolly opossum females can be modified by males, and if such an effect exists, whether chemical signals from urine of males are responsible.

\section{Materials and Methods}

Animals. Eighteen female and 8 male woolly opossums, Caluromys philander (Didelphidae, Marsupialia), were used. They had been caught $(\mathrm{N}=14)$ 3-4 years earlier at Cabassou (French Guyana, $\left.53^{\circ} \mathrm{W}, 5^{\circ} \mathrm{N}\right)$ or born $(\mathrm{N}=12)$ in captivity at the Laboratory of Ecology (Brunoy, France). All animals were adult according to dental characteristics (Atramentowicz, 1986), sexually mature and weighed $200-400 \mathrm{~g}$. In captivity, the conditions of food availability, temperature $\left(28-30^{\circ} \mathrm{C}\right)$ and relative humidity $(50 \%)$ were maintained constant as described by Perret \& Atramentowicz (1989). Animals were exposed to reverse constant artificial daylight of 12-h light/12-h dark and red lights were used during the dark phase (lights on at 13:00 h) to allow behavioural observations. For 1 month before the experiments, all animals were maintained isolated in large cages $(1 \times 1.9 \times 2.7 \mathrm{~m})$ separated by wooden partitions.

Experimental procedures. To test the influence of male stimuli on oestrous cyclicity in females, we chose an experimental period of 120 days, corresponding to a probable duration of 3 oestrous cycles, since the oestrous cycle of the woolly opossum lasts approximatively 40 days $(38 \cdot 6 \pm 1 \cdot 4, \mathrm{~N}=14$ : Perret \& Atramentowicz, 1989). In addition, because males and females exhibit circannual changes in sexual activity in the field and in captivity (Perret \& Atramentowicz, 1989), experiments were conducted at two periods of the year corresponding to increased or reduced reproductive activity: from September to January and from April to July, the breeding and non-breeding seasons respectively. Because of the small number of experimental animals and the need to account for circannual changes in sexual activity, each female was tested once or twice a year (i.e. isolated, paired or exposed to male urine during the breeding or non-breeding seasons) over a 3-year study.

At the beginning of the experiment, females were removed from the breeding colony and kept isolated in a separate room containing no males. To avoid olfactory influences, a ventilation system ensured the continuous renewal of air by external fresh air. Control females $(\mathrm{N}=11$ for the breeding and non-breeding seasons) were maintained isolated during the 120-day experiment. Females which were subjected to male influences were first isolated for 40 days (pre-stimulation phase) in the same conditions as control females. Thereafter, the females were either paired with a male (Group I) or exposed to male urine (Group II) for a period of 40 days (stimulation phase). For Group I ( 24 tests for the breeding and non-breeding seasons on 18 females among which 6 were tested twice in different years), females were placed in the cage of a male which lived in a separate room. Pairing was continuous but in several cases (11/48), discontinuous pairing ( 4 days/week) was used because the interest of males for females has been shown to be enhanced by this intermittent pairing procedure (Ben M'Barek, 1989). For Group II (10 for the breeding season and 5 for the non-breeding season), females were exposed to a pool of urine freshly collected from isolated males. Every 2 days, a round filter $(15 \mathrm{~cm}$ diam.) moistened by $2 \mathrm{ml}$ of pooled urine was introduced in the nest box of female. After the stimulation phase, Group I and Group II females were kept isolated from male influences for $\mathbf{4 0}$ days (post-stimulation phase).

Animals were routinely examined for body weight and for identification of phases of the oestrous cycle according to criteria described previously (Perret \& Atramentowicz, 1989). Urogenital smears were taken twice/week to detect the occurrence of pro-oestrous and every 2 days when females entered cytological oestrous (proliferation of epithelial 
cells) until leucocytic infiltration. The end of the cytological oestrous characterized by heavy leucocyte infiltration was designated as Day 0 of the oestrous cycle. The pattern of plasma progesterone variation during the oestrous cycle has been described and blood samples collected at 5-10-day intervals were demonstrated to be sufficient to detect a rise in plasma progesterone during the luteal phase (Perret \& Atramentowicz, 1989). Accordingly, every 5-10 days throughout the experiments, blood samples $(250 \mu \mathrm{l}$ each) were collected without prior anaesthesia, by puncture of the saphenous vein, within $5 \mathrm{~min}$ of removing the animal from its cage during the daily sleeping period. After centrifugation, plasma was stored at $-20^{\circ} \mathrm{C}$ until assayed.

Progesterone radioimmunoassay. Concentrations of progesterone were measured in 60-80 $\mu$ l plasma using the radioimmunoassay procedures described for this species by Perret \& Atramentowicz (1989). The antiserum was raised in a rabbit from progesterone 3-carboxymethyl-O coupled to bovine albumin (from Roussel UCLAF, Romainville, France). The cross-reactivities were: progesterone, $100 \%$; $5 \alpha$-pregnanedione, $32 \%$; deoxycorticosterone, $7 \cdot 3 \%$; $5 \beta$-pregnanedione, $15 \%$; $5 \alpha$-pregnane 3-ol, 20 -one, $5 \%$; other C21 steroids, $<1 \% ; \mathrm{C} 19$ steroids, $<0.01 \%$. The intra-assay coefficient of variation based on all samples tested in duplicate was $7.0 \%$ (s.d. $=5.5$ ) and the interassay coefficient was $6.7 \%($ s.d. $=4.6)$ based on 50 samples with a progesterone concentration of $8-20 \mathrm{ng} / \mathrm{ml}$. The sensitivity of the assay was $6 \mathrm{pg} /$ tube. Radioactive steroid (progesterone: sp. act. $85 \mathrm{Ci} / \mathrm{mmol}$ ) was purchased from Amersham International plc (Bucks, UK) and non-radioactive steroid from Sigma (St Louis, MO, USA).

Statistical analysis. All values are expressed as means \pm s.e.m. and statistical differences were tested using one-way analysis of variance. Each experimental phase was divided into 8 intervals of 5 days for statistical analysis of occurrence of oestrus or changes in plasma progesterone concentrations. To compare differences in distributions of oestrus within experimental females or differences between observed and theoretical distributions, we used $\chi^{2}$ tests with Yates' correction or the Kolmogoronov-Smirnov (KS) one-sample test. To assess independence and interactions among several parameters, we used the $G$ test in a three-way table. Correlation between specific characters were evaluated using linear regression analysis.

\section{Results}

\section{Control females and oestrous cycle characteristics}

Females maintained isolated without male influences (Fig. 1) spontaneously entered either one $(\mathrm{N}=11)$ or two $(\mathrm{N}=7)$ oestrous periods or showed no oestrous $(\mathrm{N}=5)$. The number of oestrous periods was lower than expected since each isolated female could have exhibited 3 oestrous periods during the 120-day isolation period. During the breeding season, the frequency of occurrence of oestrous was $1 \cdot 5 \pm 0 \cdot 2$ /female, and in the non-breeding season, the frequency was only $0 \cdot 7 \pm 0 \cdot 1$ / female. This difference is significant $\left(\chi^{2}=5 \cdot 3\right.$, d.f. $\left.1, P<0 \cdot 02\right)$, supporting the existence of a circannual cycle of activity in captive woolly opossums. However, in both seasons, the distribution of oestrous did not differ from an expected random distribution (KS $=0.09$, NS), and there was no synchronization (Fig. 1).

During the breeding season, 7 females demonstrated 2 successive oestrous periods at intervals varying from 37 to 110 days. Since the normal inter-oestrous interval is 40 days, this high variability in isolated females indicates that females were cycling irregularly.

Using progesterone values recorded in the $\mathbf{4 0}$ days following the leucocytic infiltration after cytological oestrous (Day 0, Fig. 1), providing that these 40 days were entirely included in the 120-day isolation period, a normal pattern of progesterone variation was found in 11/18 cases for control females. Progesterone concentrations increased significantly by Day 10 and remained elevated until Day 20. Thereafter hormonal values returned to basal levels (Fig. 1). The luteal phase (progesterone up to $10 \mathrm{ng} / \mathrm{ml}$, mean from Days 10 to $20: 31.6 \pm 3.8 \mathrm{ng} / \mathrm{ml}, \mathrm{N}=11$ ) could be estimated as lasting about 20 days. The next 20 days of the cycle with basal progesterone concentrations corresponded either to the follicular phase preceding the next oestrus if the female returned to oestrous or to an anoestrous state if she did not.

In the 7 remaining females, progesterone concentrations in plasma did not increase and remained constantly low, on average $4.6 \pm 0.6 \mathrm{ng} / \mathrm{ml}(\mathrm{N}=7)$. This mean value was similar to that observed in females which exhibited no sign of urogenital oestrous (mean: $4.5 \pm 0.5 \mathrm{ng} / \mathrm{ml}, \mathrm{N}=7$ ). This pattern of hormonal variation indicates an anovulatory cycle which is identical in the breeding and non-breeding seasons. 

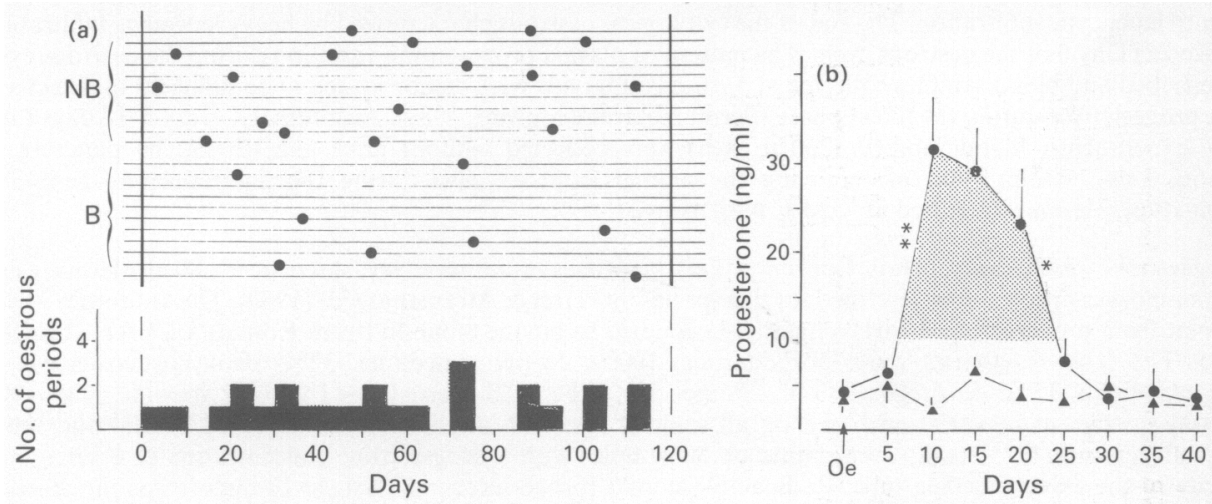

Fig. 1. Occurrence and characteristics of oestrous cycles in 11 females maintained isolated from male influences for 120 days during the breeding and non-breeding seasons. (a) Number and random distribution of oestrous periods for each female. Day 0 of one oestrous cycle determined from urogenital smears is indicated by a point. (b) Variations in mean \pm s.e.m. progesterone concentrations dated from Day 0 of the oestrous cycle. According to whether cycles were anovulatory $(\boldsymbol{\Delta}, \mathrm{N}=7$ ) or ovulatory $(\bullet, N=11)$, progesterone values remained low or increased significantly during the luteal phase (grey area). ${ }^{*} P<0.05$ and ${ }^{*} P<0.01$.

\section{Enhancement of oestrous cycles by male stimuli}

Occurrence of oestrous in stimulated females (Fig. 2). During the pre-stimulation phase, when Group I $(N=48)$ and Group II $(N=15)$ females were isolated, the number and the distribution of oestrous periods did not differ from those observed in control females during the same period $(G=8.6$, d.f. 7, NS). More numerous oestrous periods occurred in the breeding than in the nonbreeding season $(\mathrm{G}=6.7$, d.f. $1, P<0.01)$ with a distribution which did not differ from the expected random distribution (KS $=0 \cdot 15, \mathrm{NS})$.

During the stimulation phase, significant differences appeared between control females and all females exposed to male influences $(\mathrm{G}=56.5$, d.f. $7, P<0.001)$. Females exposed to male influences entered one (60/63) or even $2(3 / 63)$ oestrous periods (Fig. 2). The effect of the male was independent of season $(\mathrm{G}=1 \cdot 3$, d.f. $2, \mathrm{NS})$ and of male stimulus used since females paired with a male and females exposed only to urine reacted similarly. In Groups I and II, most of the induced oestrous periods (52/66) occurred between the 10th and the 30th day of stimulation, indicating a close synchronization between stimulated females. The frequency distribution of oestrous differed significantly from an expected random distribution $\left(\chi^{2}=29.5\right.$, d.f. $\left.7, P<0.01\right)$.

During pairing several females became pregnant and gave birth at an average of $24 \pm 0.9$ days $(\mathrm{N}=13$ ) after the observed copulation. Among other females (35 from Group I and 15 from Group II), some returned to oestrous during the post-stimulation phase (Fig. 2). During that period, the number and the distribution of oestrous periods were very similar to those of control females during the same period $(\mathrm{G}=3.84$, d.f. $7, \mathrm{NS})$ and those of all isolated females during the pre-stimulation phase $(\mathrm{G}=2 \cdot 65$, d.f. $7, \mathrm{NS})$, indicating that the stimulating effect of the male is restricted to the period of stimulation.

Role of sexual state of females before male stimulation. During the pre-stimulation phase, females were not in the same state of sexual activity since some of them had cycled while others had not. This could have interfered with the response to male stimuli. We therefore studied separately females which entered oestrous during the pre-stimulation phase (cyclic females) and females which did not (acyclic females). Data from Group I and Group II females in the breeding and nonbreeding seasons were pooled because no differences were found in their responses in relation to the male stimulus used or to the season. 

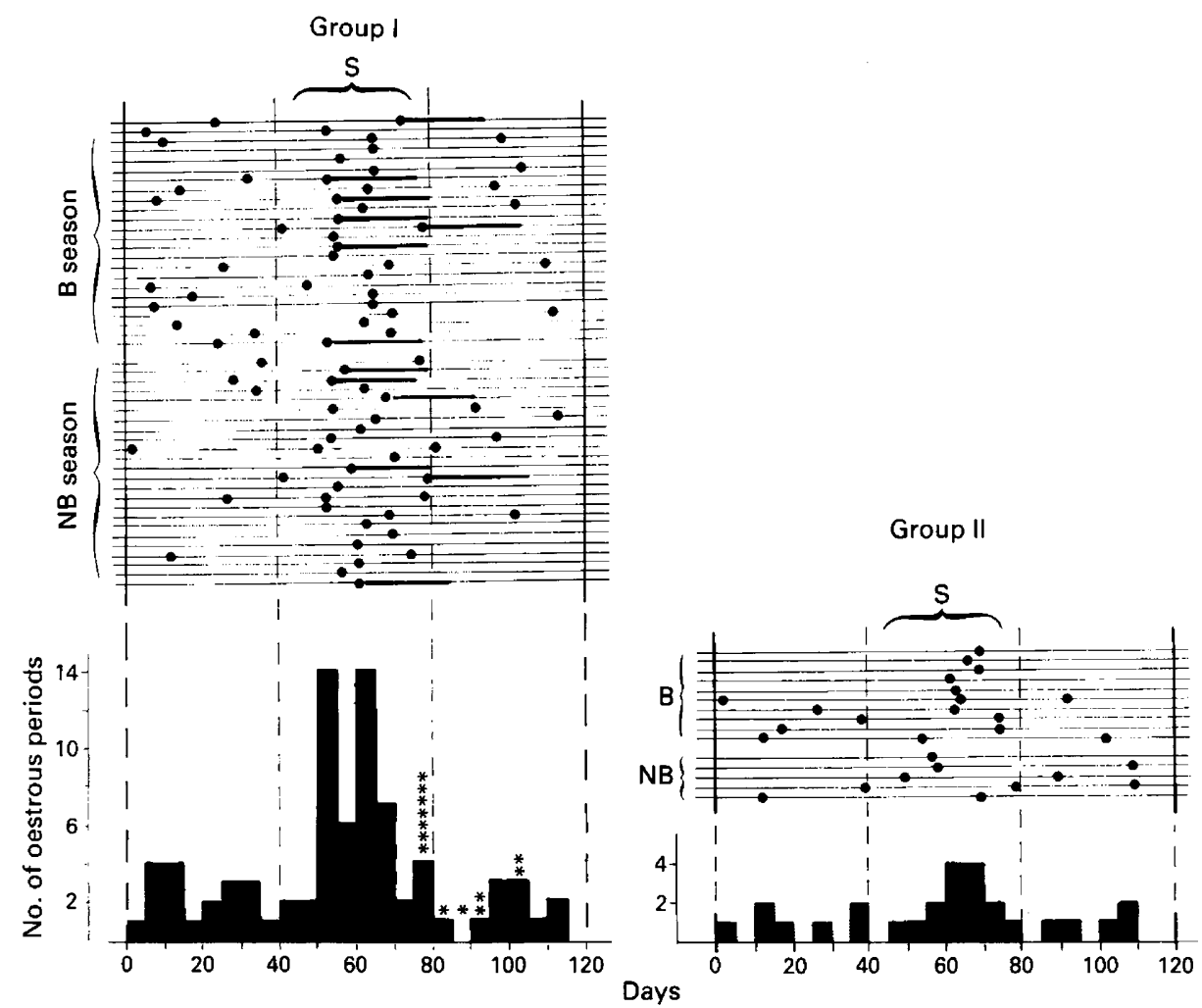

Fig. 2. Number and distribution of oestrous periods in females exposed for 40 days to male influences during the breeding and non-breeding seasons. All females paired (Group I, N = 48 tests) or exposed to pooled urine of males (Group II, N = 15 tests) entered oestrous during the stimulation phase (S). One tested female corresponds to a line and each point represents Day 0 of one oestrous cycle determined from urogenital smears. The significant enhancement of oestrus under male influences is independent of season. Several paired females became pregnant (broad line) and gave birth (*).

In acyclic females the distribution of oestrous periods induced by male stimuli was unimodal and all oestrus periods occurred from the 10th to 30th day during the stimulation phase (mean latency $=20.7 \pm 0.95$ days, $N=35$ ), independent of the male stimulus used. In 24 females (16 from Group I and 8 from Group II), progesterone concentrations were measured in plasma and were constantly low during the pre-stimulation phase $(4.3 \pm 0.4 \mathrm{ng} / \mathrm{ml})$ and during the first 2 weeks of male stimulation $(5.4 \pm 0.6 \mathrm{ng} / \mathrm{ml})$. Thereafter, changes in progesterone concentrations were observed according to whether females exhibited ovulatory, anovulatory cycles or became pregnant (see Fig. 4).

In contrast, in females which exhibited one oestrous period before male exposure $(\mathrm{N}=28)$, the distribution of oestrus during the stimulation phase followed an irregular pattern which was significantly different from that of acyclic females $(\mathrm{KS}=2.9, P<0.01)$ and cannot be explained as the normal occurrence of a second oestrus in females regularly cycling at a 40-day interval. Indeed, the interval between the oestrous periods varied from 20 to 63 days and depended upon the time when females became oestrous in the pre-stimulation phase ( $r=0.745, P<0.001$, Fig. 3 ).

If females were within 5 days of oestrous at the time when the male stimulus was applied ( $N=$ 5), they exhibited the next oestrous at the expected time, i.e. within 40 days (mean: $38 \cdot 1 \pm 1$ days), showing that male stimuli had apparently no influence on oestrous periodicity in these females (Fig. 3a). 


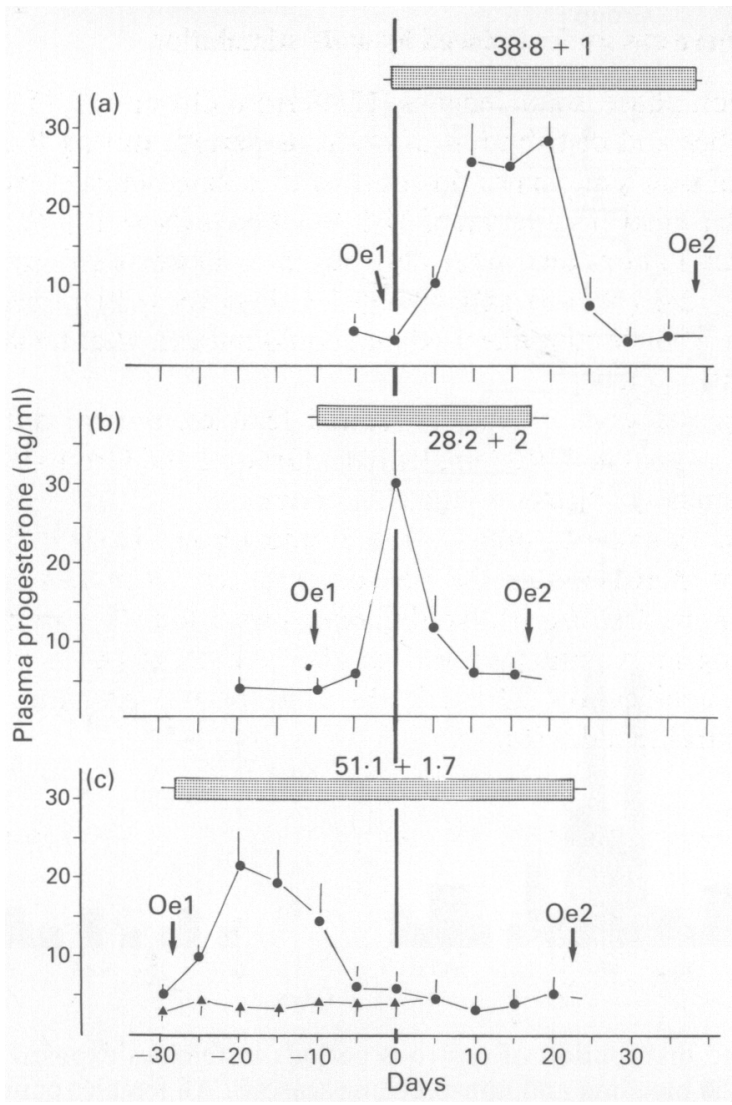

Fig. 3. Changes in progesterone concentrations (mean \pm s.e.m.) in females which exhibited one oestrus $(\mathrm{Oe})$ before male stimulation and during the stimulation phase. Days are dated from the beginning of male stimulation (0). Responses of females differ according to date of the first oestrus: (a) at $0 \pm 5$ days, $(\mathrm{N}=5)(\mathrm{b})$ at -5 to -15 days $(\mathrm{N}=7)$, (c) at -15 to -40 days $(\mathrm{N}=16)$. Means \pm s.e.m. of the inter-oestrous interval are indicated in the grey area and were significantly different.

In females which were in oestrous from 6 to 15 days before the beginning of the stimulation phase $(\mathrm{N}=7)$, plasma progesterone concentrations increased as the luteal phase proceeded, reaching $30.6 \pm 5 \mathrm{ng} / \mathrm{ml}$ at the time when females were subjected to pairing or to urine exposure (Fig. $3 b)$. The normal development of the luteal phase appeared impaired during the first days of male stimulation and a significant $(P<0.05)$ fall in progesterone values was seen within 5-10 days of male stimulation, leading to a rapid return to oestrus at a mean latency of $17 \cdot 8 \pm 2$ days. The interval between the first and the second oestrous period was therefore significantly shorter than normal (mean $28.7 \pm 2$ days, $\mathrm{N}=7, P<0.01$ ).

In females which were in oestrous from 16 to 40 days before the stimulation phase $(N=16$, Fig. 3c) progesterone concentrations were always low $(4.3 \pm 0.7 \mathrm{ng} / \mathrm{ml})$ when the stimulation phase started, indicating that the luteal phase was finished, if present (in $6 / 16$ cases, anovulatory cycles were found). All females exhibited oestrous later than expected with an inter-oestrous interval constantly and significantly lengthened (mean: $51.1 \pm 1.7$ days, $P<0.001$ ). No differences were found between anovulatory or ovulatory cycles following the first oestrous, indicating that females were in the same sexual state at the beginning of male stimulation and so cannot be considered as acyclic females. 


\section{Characteristics of the oestrous cycles induced by male stimulation}

After the stimulation phase, some females (12/48 from Group I, 5/15 from Group II) returned to oestrous. The number and distribution of oestrous periods during the post-stimulation phase were similar to those of isolated females. In contrast to isolated females, stimulated females cycled regularly at a mean inter-oestrous interval of $37.5 \pm 1.4$ days $(\mathrm{N}=17)$. When females were already cycling before male stimulation, their inter-oestrous interval was significantly shorter than that of acyclic females: $34.2 \pm 2.4(\mathrm{~N}=8)$ and $40.4 \pm 1.3$ days $(\mathrm{N}=9)$ respectively $(P<0.05)$. This effect was independent of male stimulus used and could indicate that females already cycling were more responsive to male stimuli.

Compared with spontaneous cycles of isolated females, several differences (assessed using progesterone values measured in 47/53 females from Group I and Group II) could be demonstrated in oestrous cycles of females subjected to male influences.

Anovulatory cycles. In some Group I $(\mathrm{N}=5)$ and Group II $(\mathrm{N}=6)$ females, progesterone concentrations did not increase after the oestrous induced by male stimulation, indicating the presence of anovulatory cycles (Fig. 4). No differences were found in progesterone values between all females experiencing anovulatory cycles but the percentage of anovulatory cycles in paired females $(13.5 \%)$ was significantly $(\mathrm{G}=7 \cdot 2$, d.f. $2, P<0.02)$ less than that for urine-exposed females $(40 \%)$ and control females $(61 \%)$.
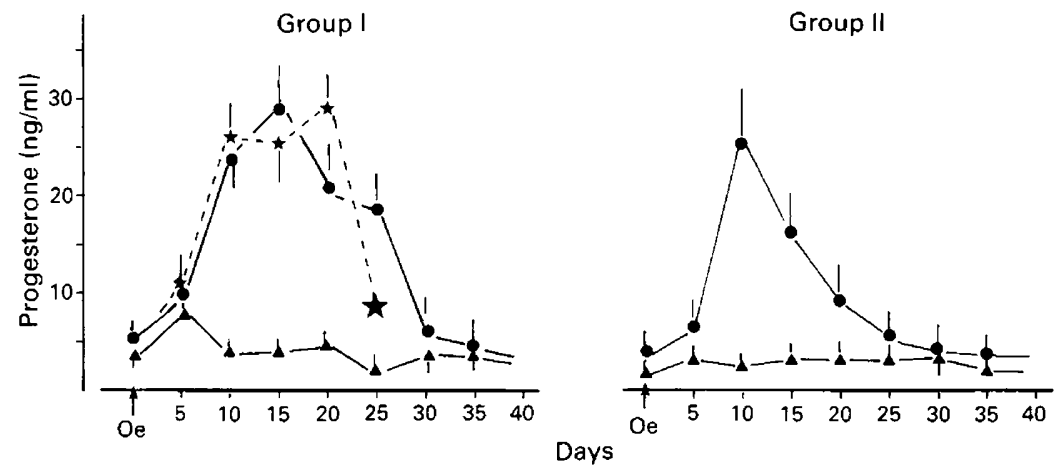

Fig. 4. Variations in progesterone concentrations (mean \pm s.e.m.) dated from Day 0 of the oestrous induced by pairing (Group I) or exposure to male urine (Group II) and according to whether oestrous cycles were anovulatory $(\Delta, N=5$ in Group I and $N=6$ in Group II) or ovulatory $(\bullet, N=19$ in Group I and $N=9$ in Group II). Progesterone profiles in pregnant females are indicated $(\star, N=8)$ until the occurrence of birth $(\star)$.

Ovulatory cycles. After oestrous, progesterone concentrations in paired females increased significantly from Day 10 and reached a mean value of $25.5 \pm 2.2 \mathrm{ng} / \mathrm{ml}(\mathrm{N}=19)$ during the luteal phase, a value which did not differ from the mean value found in control females. But luteal activity in paired females was more sustained than in control females since progesterone concentrations only decreased significantly at Day $25(P<0.05$, Fig. 4). In 8 females which became pregnant during the stimulation phase, variations in plasma progesterone concentrations were similar to those in non-pregnant cycles, with mean progesterone concentrations of $26.6 \pm 2.4 \mathrm{ng} / \mathrm{ml}$ during the luteal phase (Fig. 4).

In $9 / 15$ females exposed to male urine, ovulatory cycles were found but, although progesterone concentrations increased significantly at Day 10 as in control or in Group I females, values became basal as early as Day 20. The luteal phase in urine-exposed females was shortened, with progesterone values significantly lower (mean $18.7 \pm 2.4 \mathrm{ng} / \mathrm{ml}, \mathrm{N}=9, P<0.02$ ) than those found in ovulatory cycles of control or paired females. 


\section{Discussion}

In the breeding colony, females enter 2-3 successive spontaneous oestrous periods then remain acyclic for several months (Perret \& Atramentowicz, 1989). When females live isolated from social influences, the frequency of oestrous varies according to the circannual pattern of ovarian activity but the proportion of females entering oestrous is always lower than expected (mean $40 \%$ ). The presence of an adult male induces in $100 \%$ females a reactivation of ovarian activity leading to the occurrence of oestrous within about 20 days of male stimulation. The stimulating effect of the male can be reproduced by using only a pool of male urine, providing evidence that the male effect depends on pheromonal cues.

In anoestrous females, the male induces the onset of a follicular state and females come into oestrous about 20 days later, a latency which agrees with the previously estimated duration of the follicular phase (Perret \& Atramentowicz, 1989). Similar results were found in Monodelphis domestica and exposure to male stimuli is associated with follicular growth (Baggott et al., 1987) and increased oestrogen concentrations (Fadem, 1989). Nevertheless, the synchronization of responses in stimulated anoestrous females is not as high as expected: induced oestrous periods occur from 10 to 30 days after male exposure. Such variability in oestrous response has been described for other marsupial species for which data on the male effect exist (Baggott et al., 1987; Fadem, 1989) and appears similar to results obtained in seasonally anoestrous ewes exposed to rams (Signoret \& Lindsay, 1982; Izard, 1983). The variability of responses has been explained by the presence in some females of a silent ovulation shortly after male stimulation. This silent ovulation, related to an abnormally short cycle, precedes the occurrence of a normal follicular phase resulting in oestrous. In opossum females which exhibit a delayed oestrous, this mechanism is highly probable since a transient increase of epithelial cells is frequently found in urogenital smears about 5-10 days after male exposure. It could also be present in females already in the follicular state when exposed to male stimuli, resulting in delayed oestrous and thus in lengthening of the inter-oestrous interval.

In females which are stimulated just when they enter into oestrous, the response to male stimuli is not apparent, suggesting that, at the time of oestrous, hormonal equilibrium (increased oestrogens and LH) can only be reinforced by the male effect. In contrast, in cyclic females in which progesterone concentrations were high when male stimulation is applied, the primary effect of male signals is to depress the luteal function, resulting in a rapid return to oestrous. Such luteolytic effects of the male have been reported for pseudopregnant or early pregnant mice (Ryan \& Schwartz, 1980). The regulation of oestrous cycles by pheromonal cues from males in the woolly opossum appears identical to that found in eutherians, suggesting that pheromonal action on reproductive function could be a general regulatory pattern present in mammals from very primitive species such as the didelphids to primates (Schilling \& Perret, 1987; Barrett \& Abbott, 1989).

In didelphids, high progesterone concentrations during the luteal phase are related to the large number of ova (from 15 to 40) shed at one ovulation (Harder \& Fleming, 1981; Roger \& Bedford, 1982; Tyndale-Biscoe \& Renfree, 1987). During the male-induced oestrous cycle, changes in progesterone concentrations vary according to whether the female has been paired to a male or exposed only to male urine. No differences in luteal phase are seen between pregnant and nonpregnant paired females, while the luteal phase is shortened in urine-exposed females. Perhaps the olfactory cues presented by a disc soaked in urine do not have the same impact as does the male. Nevertheless, other exogenous factors from the male would be necessary for a full response. The low number of pregnant females and the incidence of anovulatory cycles in continuously paired females reinforce this hypothesis. Indeed, continuously paired animals systematically exhibit avoidance behaviours which inhibit sexual contacts. These avoidance behaviours do not occur when discontinuous pairing is used, leading to normal ovulatory cycles or successful pregnancies $(7 / 11)$. 
The enhancement of oestrous cycles by pheromonal cues from males would have an adaptive value in free-living opossums. Their spatial organization is well known from radiotracking methods used in French Guyana (Atramentowicz, 1982; Charles-Dominique, 1983; Julien-Laferrière, 1989). Opossums are solitary with overlapping home ranges and their nocturnal activity is mainly centred around fruiting trees. Therefore, the local concentration of individuals reflects the dispersion of food resources rather than social bonding. Woolly opossums disperse chemical signals during their nocturnal activity through mainly anogenital and urine dribbling, marking behaviours described in other didelphids (Russell, 1985; Holmes, 1987). During the rainy season, food resources are abundant and regularly distributed in the forest, a situation which does not favour chemocommunication between individuals. At the end of the rainy season, when the fruiting trees are greatly reduced in number and irregularly distributed, animals are regrouped around the remaining productive areas. At that time, most females have already stopped breeding because of the reduction in fruit production. High local concentrations of individuals feeding in the same area allow an increase in the frequency of social interactions (direct contacts or chemical signals) which would lead to both high testosterone concentrations in males (Perret \& Atramentowicz, 1989) and resumption of oestrous cycles in females. A subsequent wave of synchronous oestrous periods occurs, resulting in the seasonal peak of births observed at the end of the dry season. Ecological constraints, i.e. period of limited food resources, would primarily result in cessation of reproduction (Atramentowicz, 1982) and thereafter be responsible for the onset of the seasonal breeding period through behavioural patterns and chemosensory mechanisms.

We thank Professor J. Roffi for permission to use the technical facilities of the laboratory of Endocrinology (University Paris IX, Orsay), Roussel UCLAF for the gift of progesterone antiserum and Mme M. T. Brisset for expert maintenance of the animals.

\section{References}

Atramentowicz, M. (1982) Influence du milieu sur l'activité locomotrice et la reproduction de Caluromys philander (L.). Revue d'Ecologie (Terre \& Vie) 36, 373-395.

Atramentowicz, M. (1986) Dynamique de population chez trois Marsupiaux didelphidés de Guyane. Biotropica 18, 136-149.

Barrett, J. \& Abbott, D.M. (1989) Pheromonal cues suppress ovulation in subordinate female marmoset monkeys, Callithrix jacchus. J. Reprod. Fert., Abstr. Ser. 3, Abstr. 33.

Baggott, L.M., Davis-Buttler, S. \& Moore, H.D.M. (1987) Characterization of oestrus and timed collection of oocytes in the grey short-tailed opossum, Monodelphis domestica. J. Reprod. Fert. 79, 105-114.

Ben M'Barek, S. (1989) Reproduction chez Caluromys philander: effet mâle et comportement sexuel. D.E.A. Université Paris XIII.

Bronson, F.M. \& McMillan, B. (1983) Hormonal responses to primer pheromones. In Pheromones and Reproduction in Mammals, pp. 175-197. Ed. J. G. Vandenbergh. Academic Press, New York.

Charles-Dominique, P. (1983) Ecology and social adaptations in didelphid marsupials: comparison with eutherians of similar ecology. In Advances in the Study of Mammalian Behavior, pp. 395-422. Eds J. F. Eisenberg \& D. G. Kleiman. American Society of Mammalogists, Philadelphia.

Dickman, C.R. (1985) Effects of photoperiod and endogenous control on timing of reproduction in the marsupial genus Antechinus. J. Zool., Lond. 206, 509-524.

Fadem, B.H. (1985) Evidence for the activation of female reproduction by males in a marsupial: the grey short tailed-opossum (Monodelphis domestica). Biol. Reprod. 33, 112-116.

Fadem, B.H. (1987) Activation of estrus by pheromones in a marsupial: stimulus control and endocrine factors. Biol. Reprod. 36, 328-332.

Fadem, B.H. (1989) The effects of pheromonal stimuli on estrus and peripheral plasma estradiol in female grey short-tailed opossums (Monodelphis domestica). Biol Reprod. 41, 213-217.

Fadem, B.H. \& Rayve, R.S. (1985) Characteristics of the oestrous cycle and influence of social factors in grey short-tailed opossums (Monodelphis domestica). $J$. Reprod. Fert. 73, 337-342.

Harder, J.D. \& Fleming, M.W. (1981) Estradiol and progesterone profiles indicate a lack of endocrine recognition of pregnancy in the opossum. Science, NY 212, 1400-1403.

Holmes, J.D. (1987) Social complexity and potential for chemocommunication in captive virginia opossums, Didelphis virginiana. Ph.D. thesis., Bowling Green State University.

Izard, M.K. (1983) Pheromones and reproduction in domestic mammals. In Pheromones and Reproduction in Mammals, pp. 253-285. Ed. J. G. Vanderbergh. Academic Press, New York. 
Julien-Laferrière, D. (1989) Utilisation de l'espace et des ressources alimentaires chez Caluromys philander (Marsupial, Didelphidae) en Guyane française. Comparaison avec Potos flavus (Eutheria, Procyonidae). Thèse de Doctorat, Université Paris XIII.

McClintock, M.K. (1983) Pheromonal regulation of the ovarian cycle enhancement, suppression and synchrony. In Pheromones and Reproduction in Mammals, pp. 113-149. Ed. J. G. Vandenbergh. Academic Press, New York.

Pellissier-Scott, M.P. (1986) The timing and synchrony of seasonal breeding in the marsupial Antechinus stuartii: interaction of environmental and social cues. J. Mammal. 67, 551-560.

Perret, M. \& Atramentowicz, M. (1989) Plasma concentrations of progesterone and testosterone in captive woolly opossums (Caluromys philander). J. Reprod. Fert. 85, 31-41.

Rodger, J.C. \& Bedford, J.M. (1982) Induction of oestrus, recovery of gametes and timing of fertilization events in the opossum Didelphis virginiana. $J$. Reprod. Fert. 64, 156-159.

Russell, E.M. (1985) The metatherians: Order Marsupialia. In Social Odours in Mammals, Vol. 1, pp. 45-104. Eds R. E. Brown \& D. W. McDonald. Oxford University Press.
Ryan, E.L. \& Schwartz, N.B. (1980) Changes in serum hormone levels associated with male induced ovulation in group-housed adult female mice. Endocrinology 106, 959-966.

Schilling, A. \& Perret, M. (1987) Chemical signals and reproductive capacity in a male prosimian primate (Microcebus murinus). Chem. Senses 12, 143-158.

Signoret, J.P. (1980) Effect of the male presence on the reproductive mechanisms in female mammals. Reprod. Nutr. Dev. 20, 457-468.

Signoret, J.P. \& Lindsay, D.R. (1982) The male effect in domestic mammals: effect on LH secretion and ovulation. Importance of olfactory cues. In Olfaction and Endocrine Regulation, pp. 63-72. IRL Press, London.

Smith, M.J., Bennett, J.M. \& Chesson, C.M. (1978) Photoperiod and some other factors affecting reproduction in female Sminthopsis crassicaudata (Marsupiala: Dasyuridae) in captivity. Aust. J. Zool. 26, 449-463.

Tyndale-Biscoe, H. \& Renfree, M. (1987) Reproductive Physiology of Marsupials. Cambridge University Press.

Received 11 June 1990 